\title{
Towards Current Rectification: Nanoscale Electronic Devices based on Langmuir-Blodgett Films of Phenolate-based Homobimetallic Iron(III) Complex
}

\author{
Isuri Weeraratne
}

Advisor: Prof. Cláudio Verani

Department of Chemistry

Wayne State University 


\section{Introduction}

- Rectifiers are electronic components, govern the directional flow of current

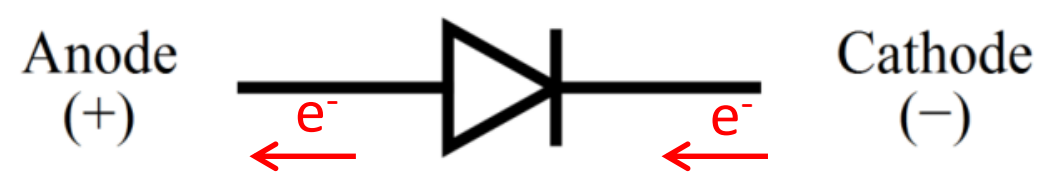

- Used in computers and microelectronic devices

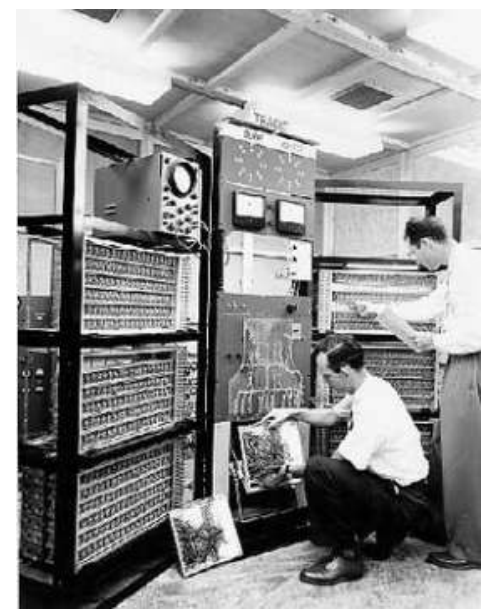

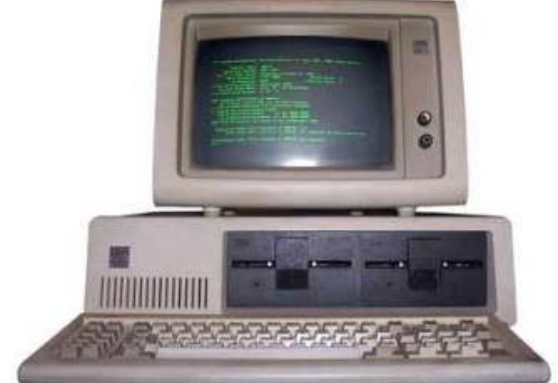

Integrated Circuits (1960s and 70s)

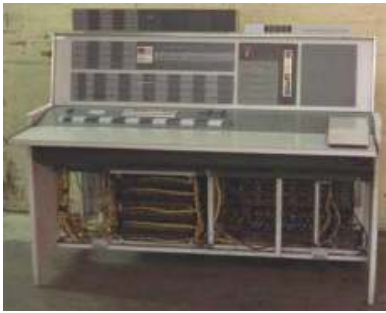

Transistors (1950s and 1960s)

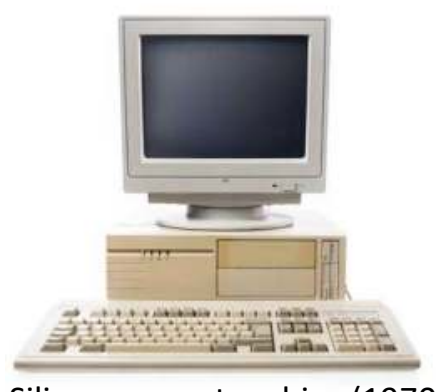

Silicon computer chips (1970s and on)

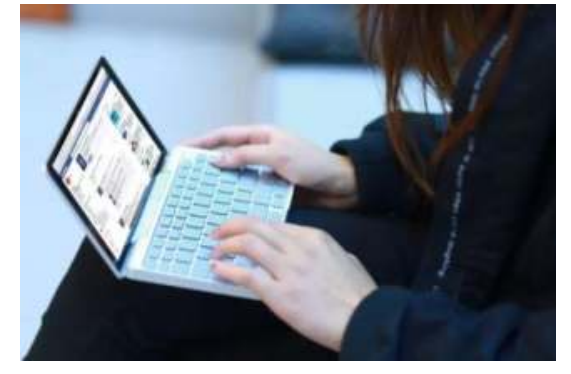

Silicon computer chips (present)

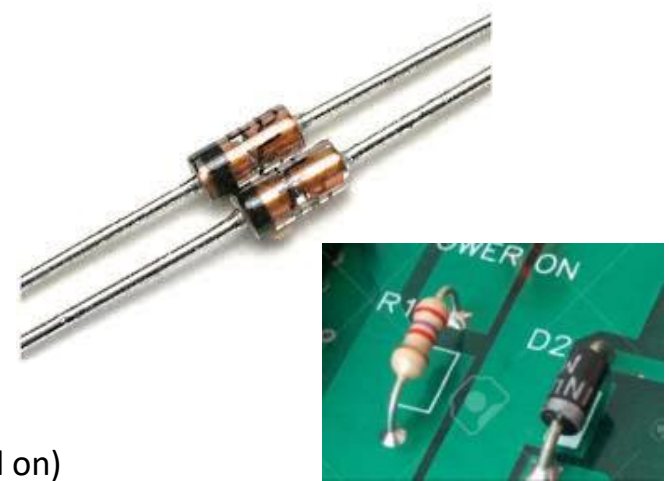

https://www.tutorialspoint.com/computer fundamentals/computer generations.htm 


\section{Molecular Rectification}

- Richard P. Feynman introduced molecules for information storage

- In 1974, Aviram and Ratner proposed the concept of molecular rectification
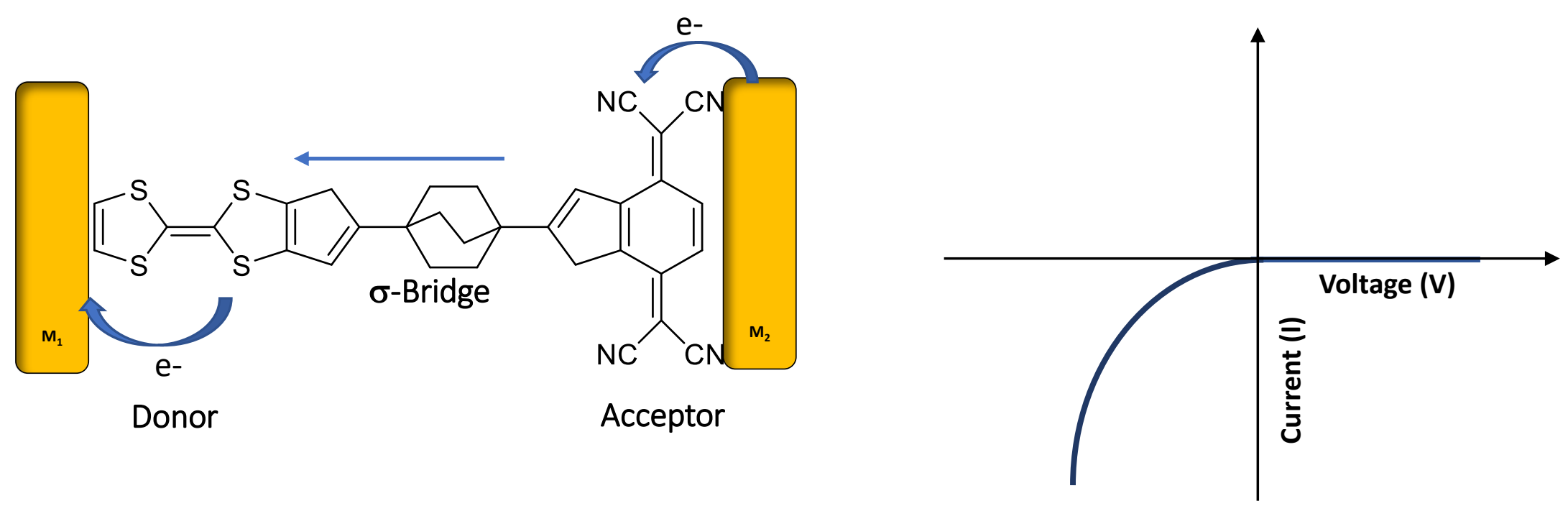


\section{LB Film : Compression and BAM Behavior}

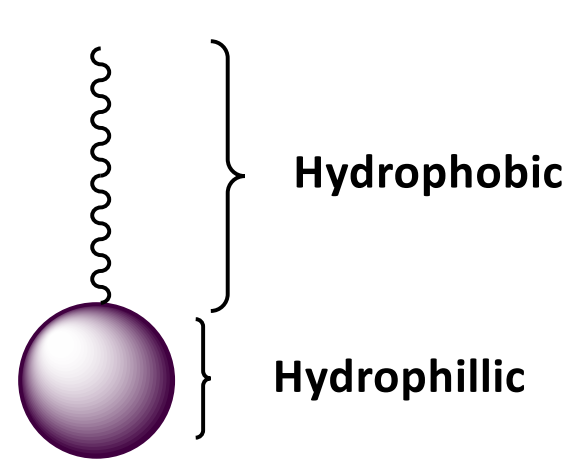

Isothermal compression

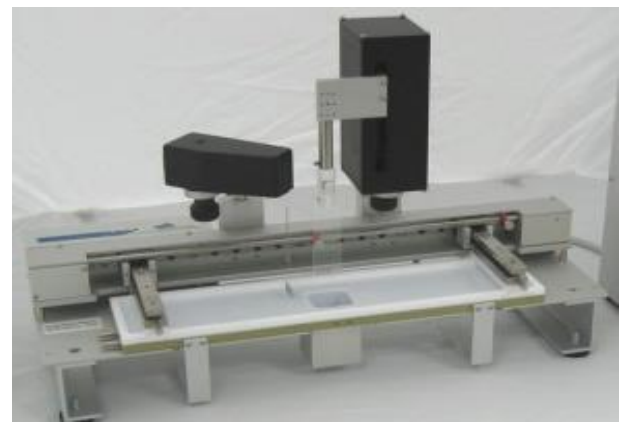

Brewster angle microscopy

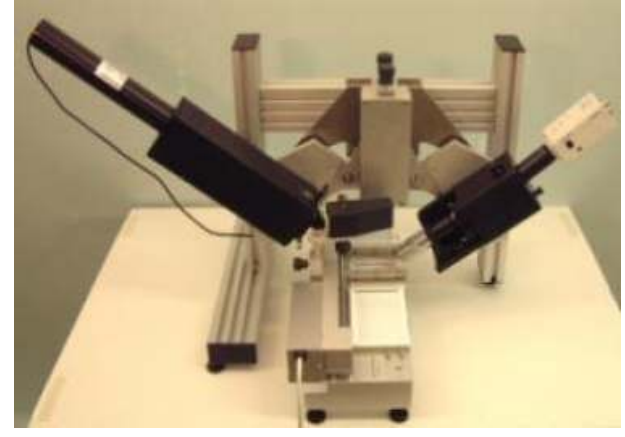

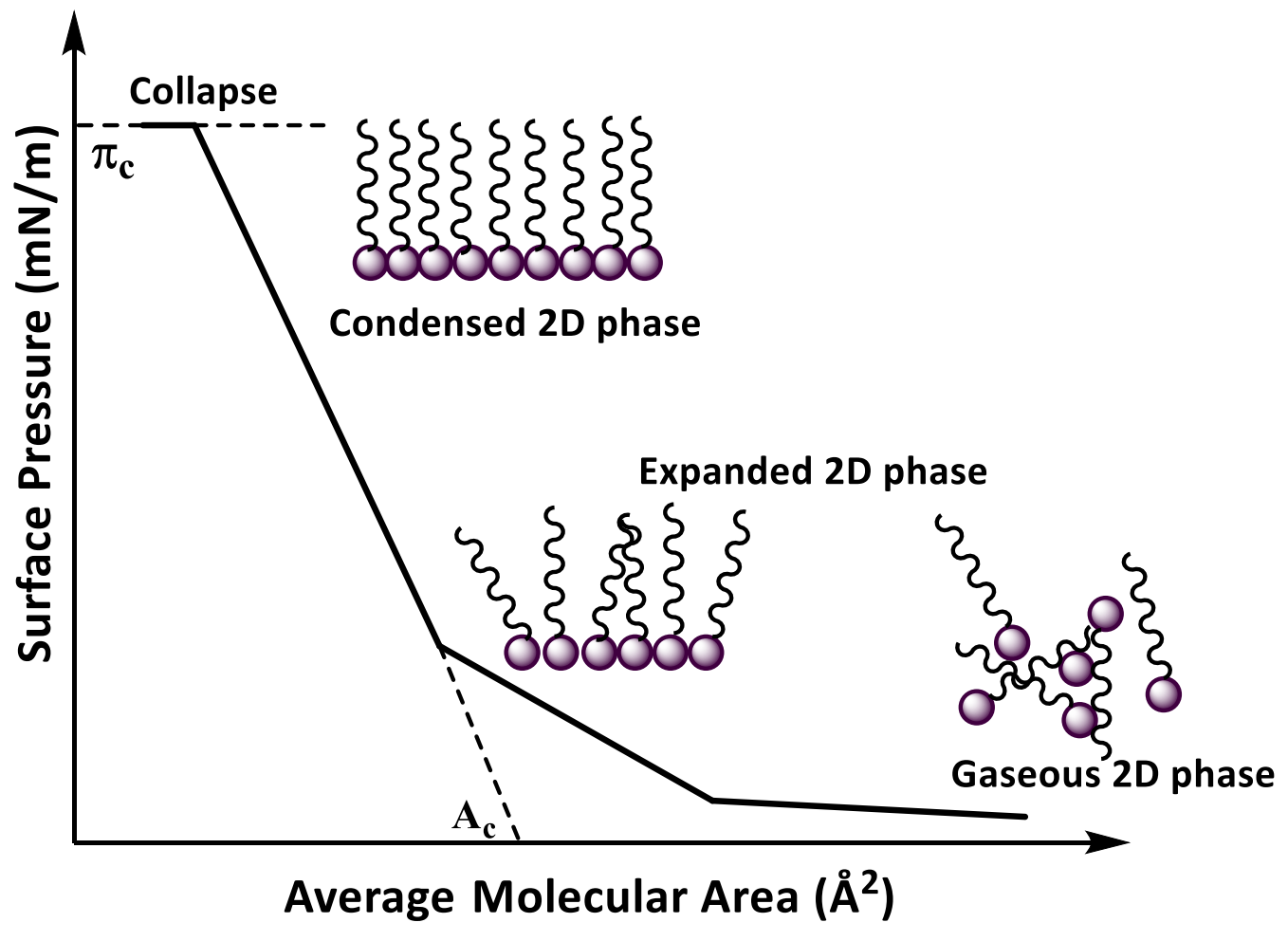

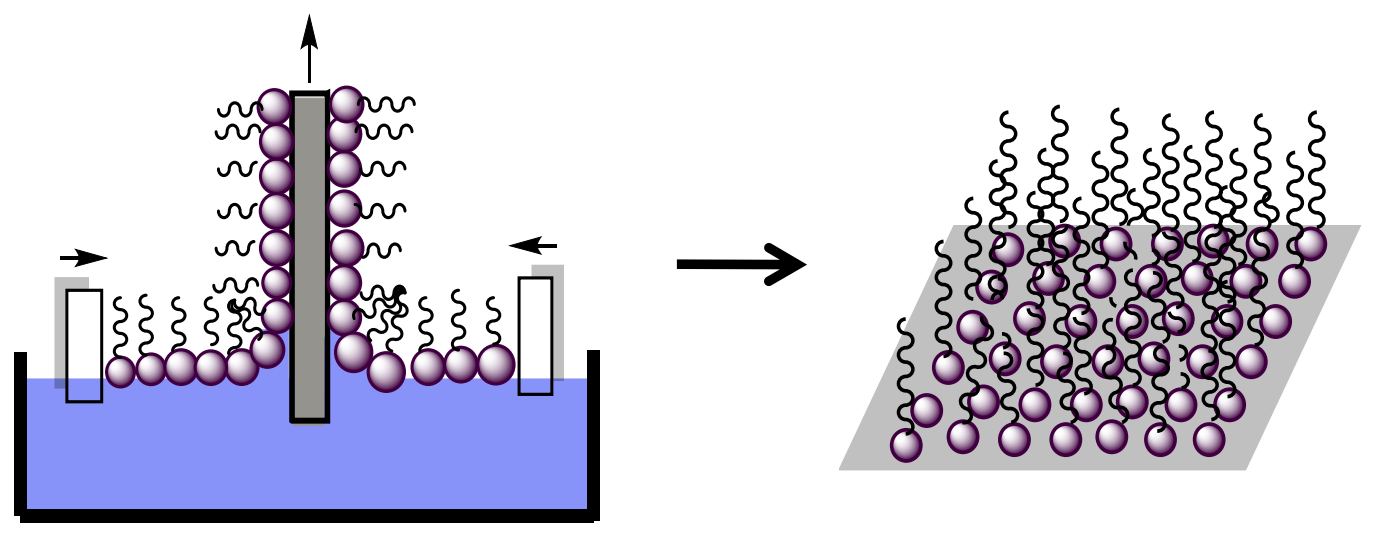




\section{Rectification in Nanoscale Devices}

- A pentacoordinate trisphenolate iron(III) complex has shown rectification behavior in gold | molecule|gold assemblies
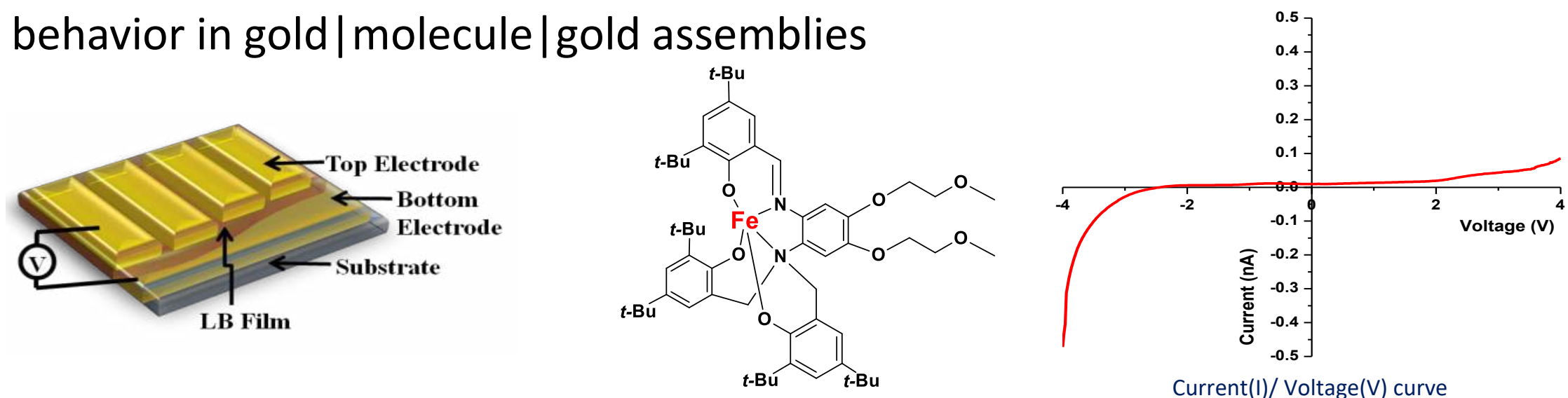

Current(I)/Voltage(V) curve

- Comparison between bisphenolate iron(III) complex and $\mathrm{Cu}(\mathrm{II}) \mathrm{Complex}$
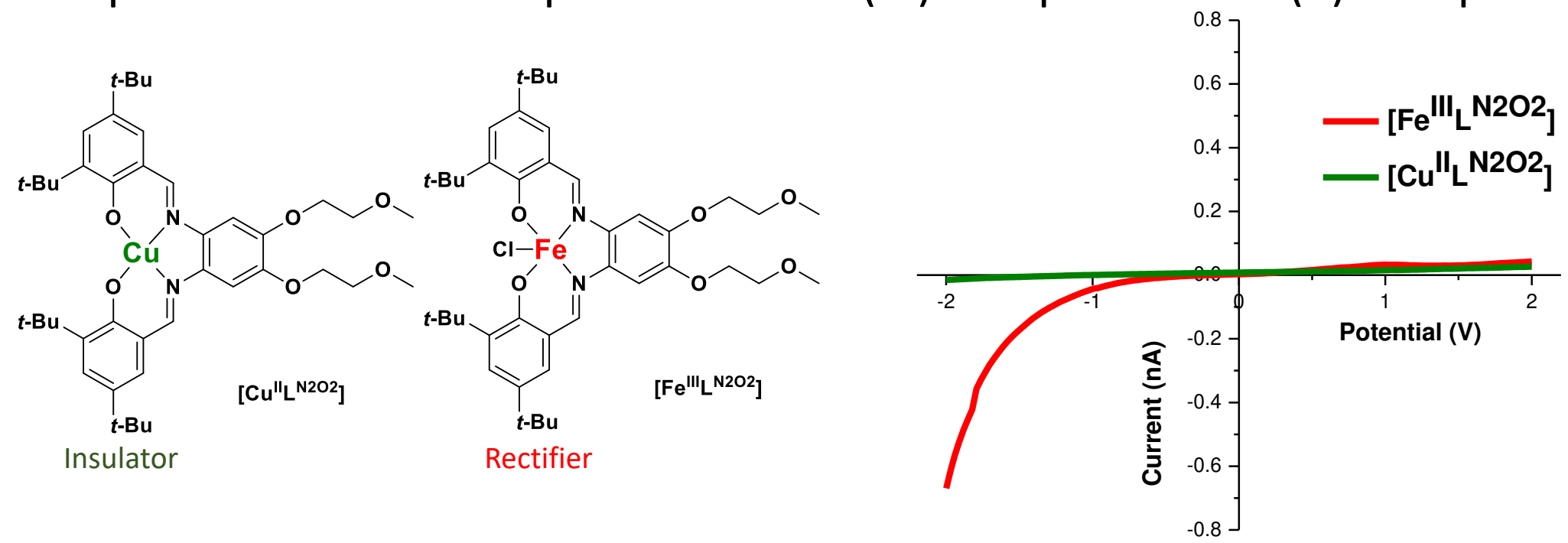


\section{Current Rectification Mechanism}

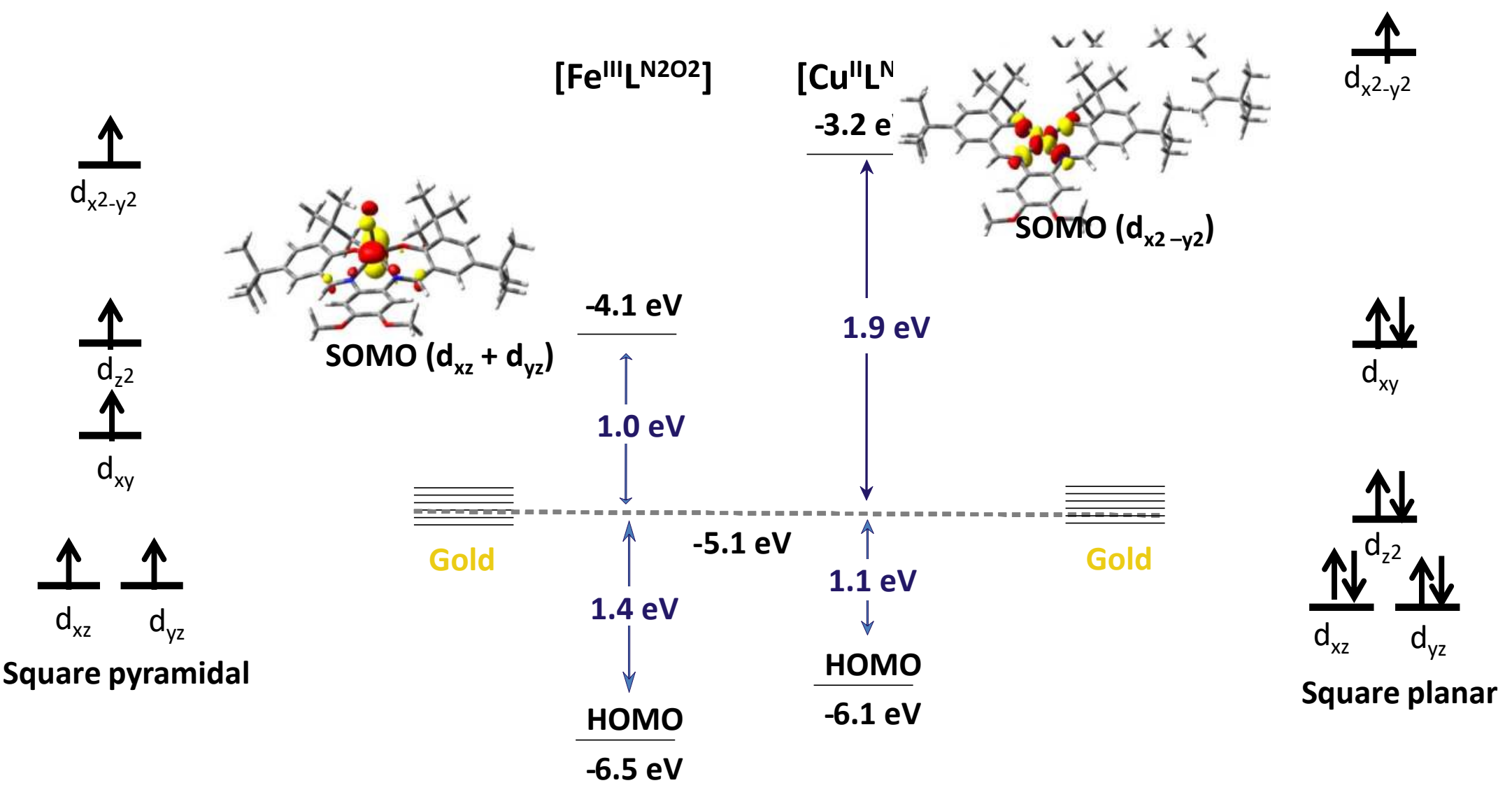

- Electrochemical(V) potentials are converted to solid-state potentials(eV) using the equations below

(LUMO/SOMO) $\mathrm{V}_{\mathrm{a}}=4.7 \mathrm{eV}+\mathrm{E}^{1 / 2}{ }_{\text {red }}(\mathrm{SCE})$

$(\mathrm{HOMO}) \mathrm{V}_{\mathrm{i}}=4.7 \mathrm{eV}+(1.7) \mathrm{E}^{1 / 2}{ }_{\text {ox }}(\mathrm{SCE})$ 


\section{$\underline{\text { Rectification with Bimetallic Systems }}$}

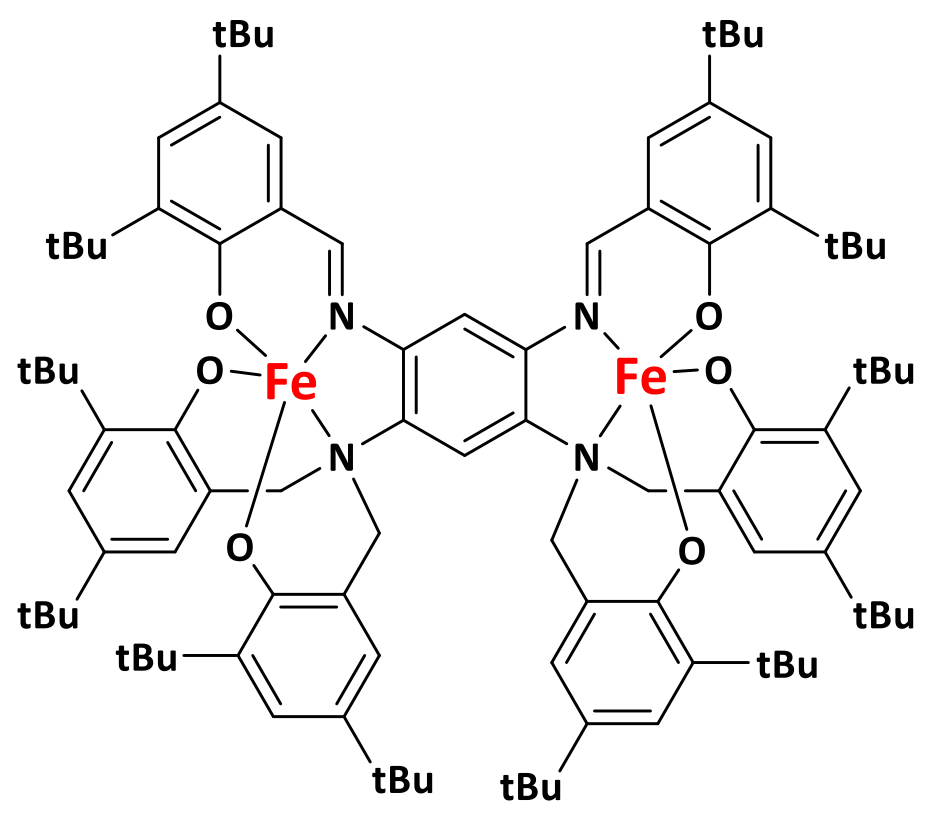

- We hypothesize that the use of a bimetallic $\left[\mathrm{Fe}^{\mathrm{III}}\right]_{2}$ system could lead to electronic coupling of the metal centers and will facilitate SOMO-based electron transfer and more than one HSFelll center may "amplify" the number of electrons being transferred by molecule and expected to enhance the rectification behavior of our assembly 


\section{Synthetic Scheme}<smiles>CC(C)(C)c1cc(CCl)c(O)c(C(C)(C)C)c1</smiles><smiles>Nc1cc(N)c(N)cc1N</smiles>
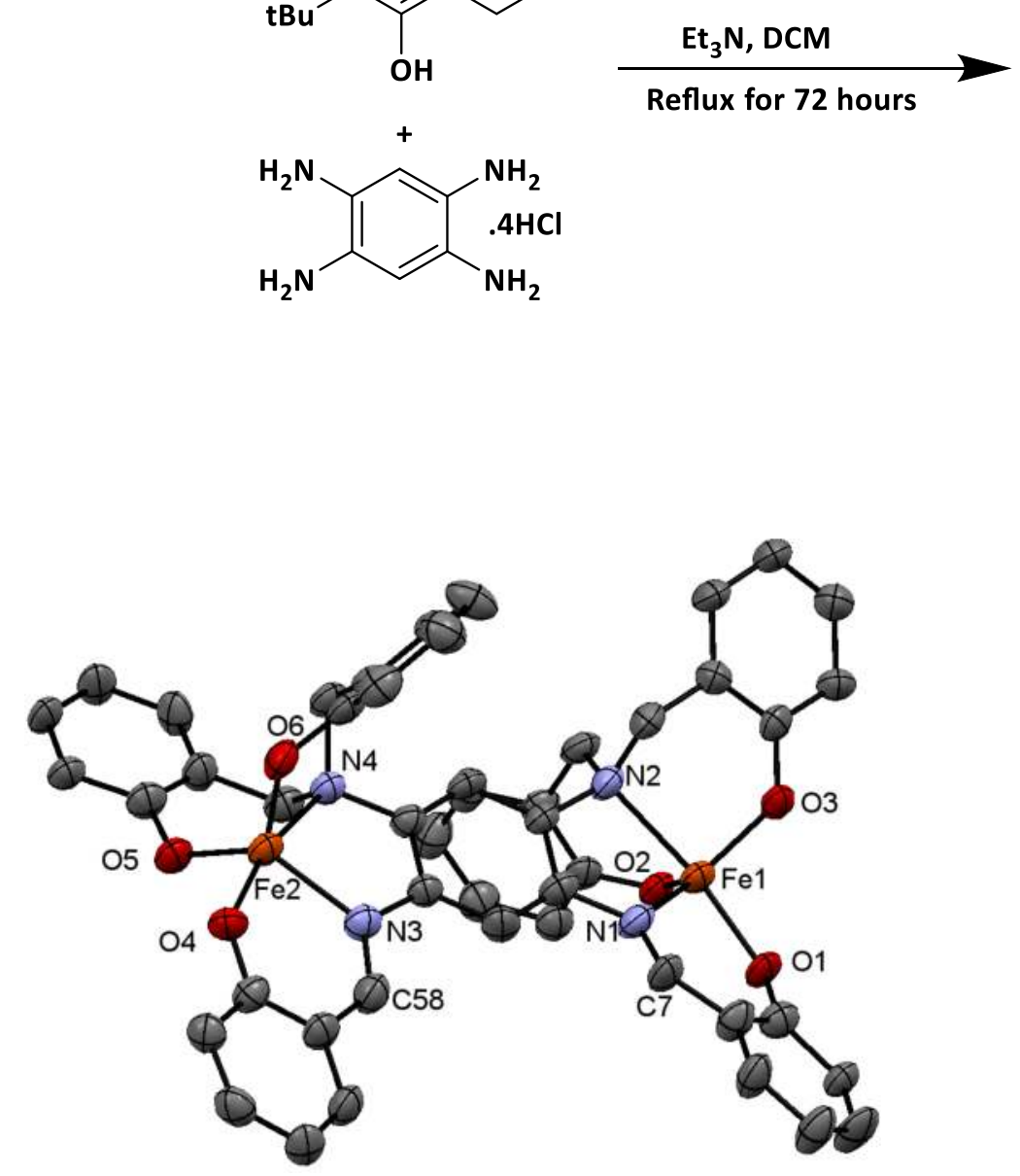
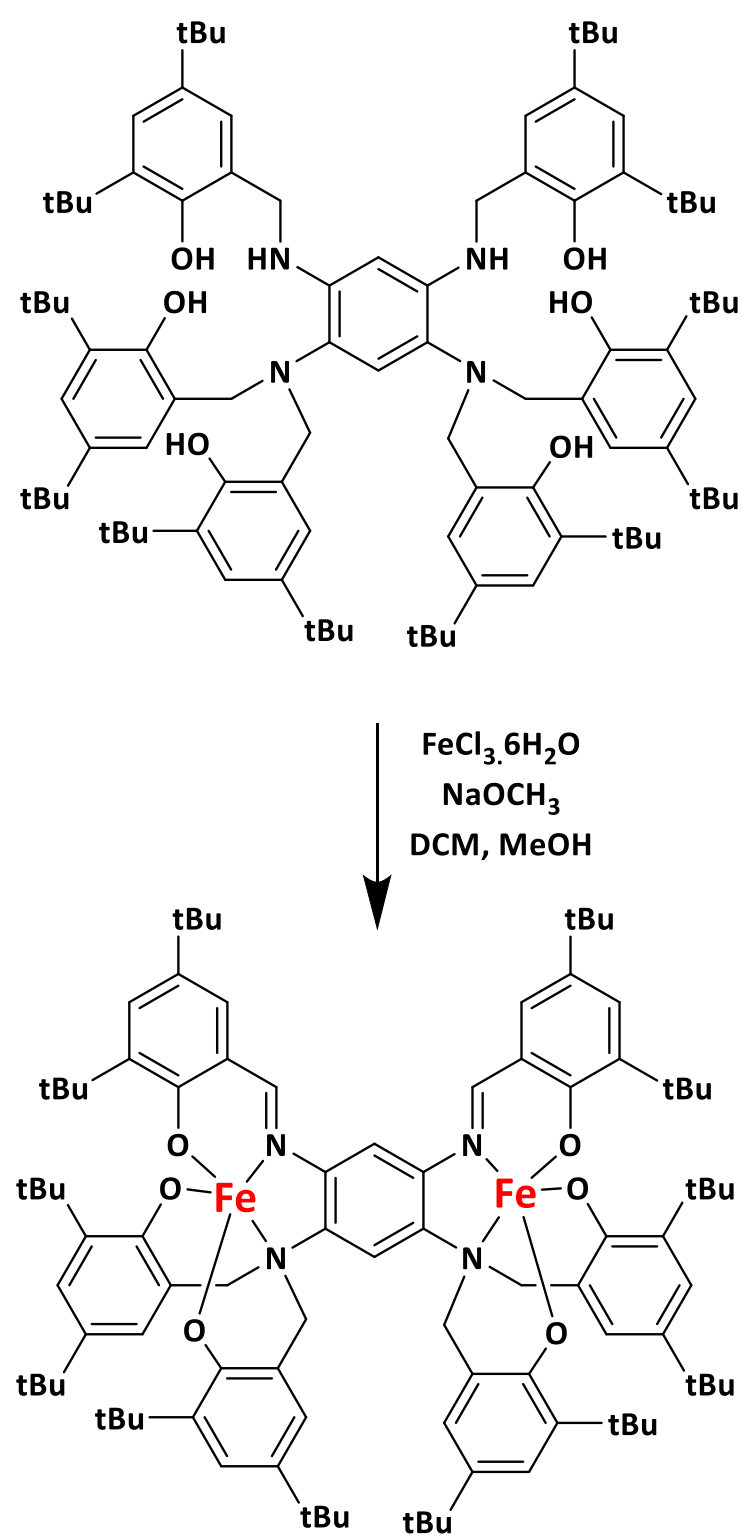

Weeraratne, Baydoun and Verani et al., Dalton Trans. 2018, 47, 14351 


\section{Electronic Structure}

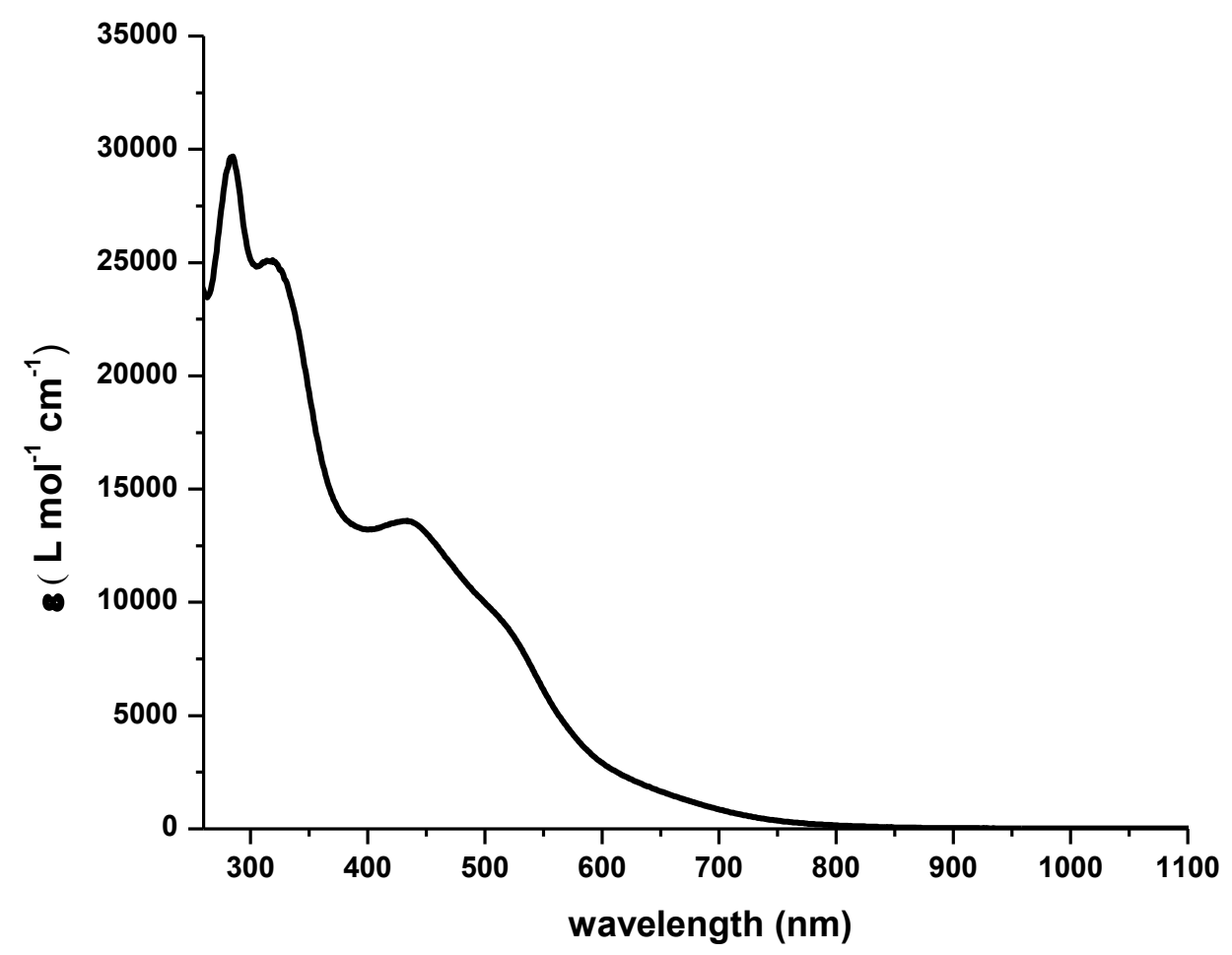

- Intraligand charge transfer band is shown at $285 \mathrm{~nm}\left(\varepsilon \approx 29,700 \mathrm{M}^{-1} \mathrm{~cm}^{-1}\right)$

- Ligand to metal charge transfer(LMCT) bands are found at $320,434 \mathrm{~nm}\left(\varepsilon \approx 25,000 \mathrm{M}^{-1} \mathrm{~cm}^{-1}\right.$ and $\varepsilon \approx 13,600 \mathrm{M}^{-1} \mathrm{~cm}^{-1}$ ) 


\section{$\underline{\text { Redox Behavior }}$}

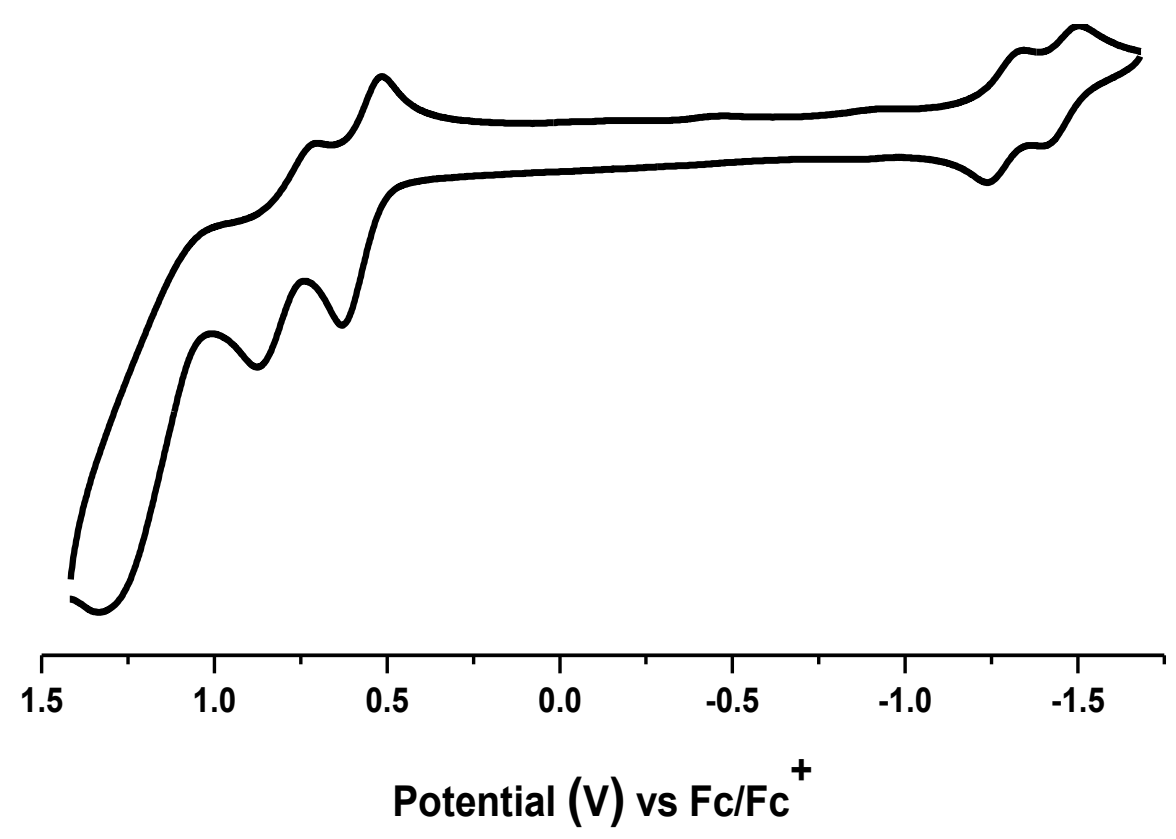

- Three two-electron oxidation process at $0.57,0.79$ and $1.17 \mathrm{~V}_{\mathrm{Fc} / \mathrm{Fc}+}$ is attributed to conversion of phenenolate to phenoxyl radical

- The two reduction wave observed at -1.27 and $-1.44 \mathrm{~V}_{\mathrm{Fc} / \mathrm{Fc}+}$ is attributed to the sequential reduction of $\left[\mathrm{Fe}^{\prime \prime \prime} \mathrm{Fe}^{\prime \prime \prime}\right] \rightarrow\left[\mathrm{Fe}^{\prime \prime \prime} \mathrm{Fe}{ }^{\| l}\right] \rightarrow\left[\mathrm{Fe}^{\prime \prime} \mathrm{Fe}^{\| l}\right]$ 


\section{Electronic Environment After Reduction}

(a) Monometallic [Fe"l']

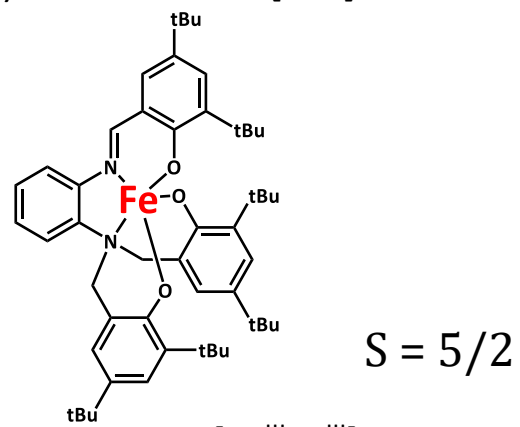

(b) AF-coupled [Fe"ll' Fe"III]

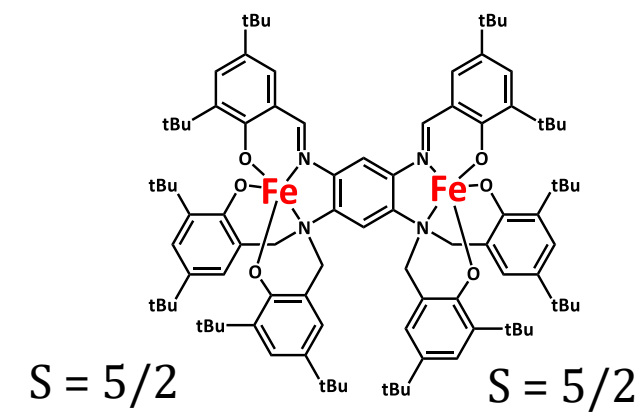

(c) AF-coupled [Fe"III $\left.F e^{\prime \prime}\right]$ with demetallation
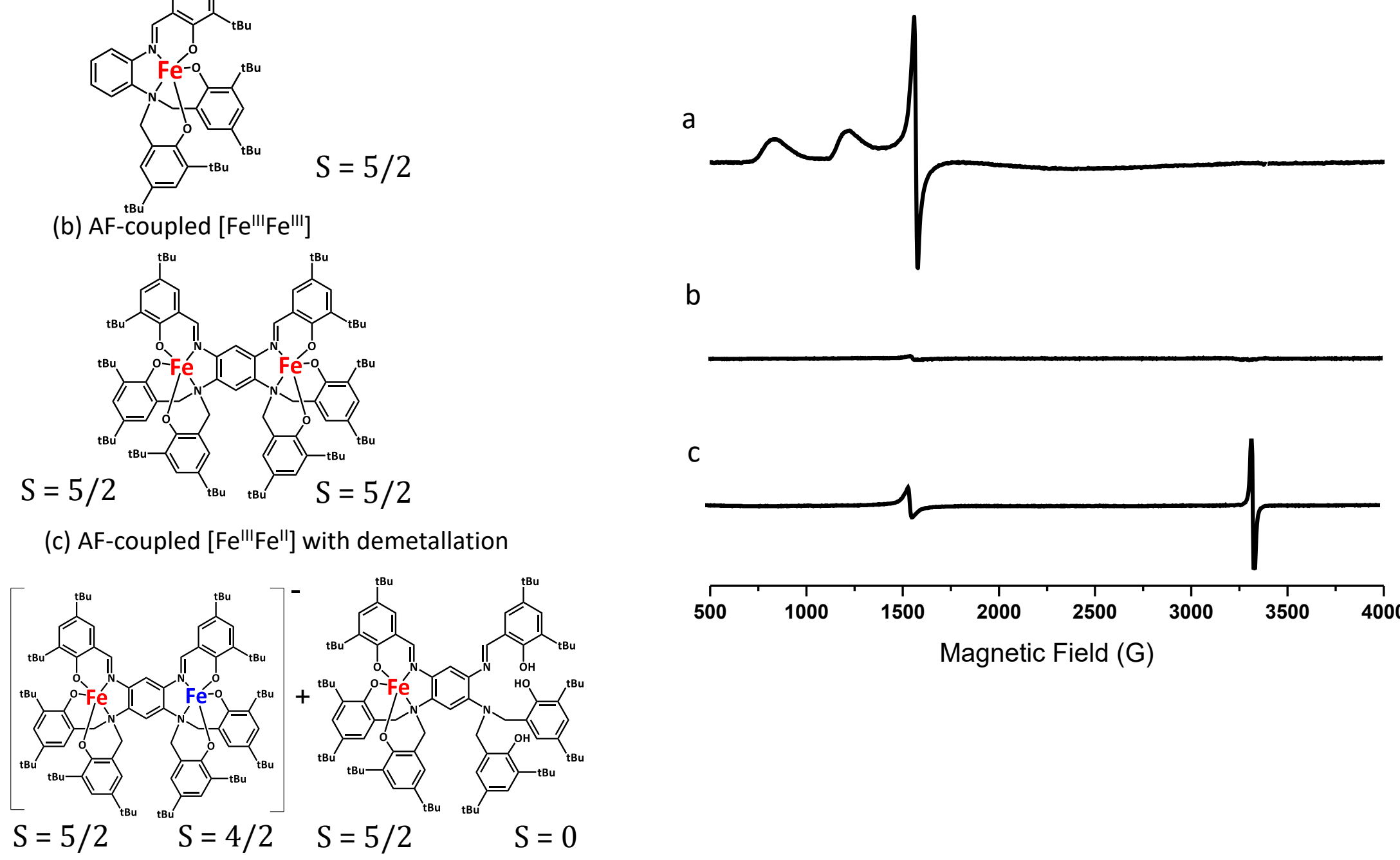

b

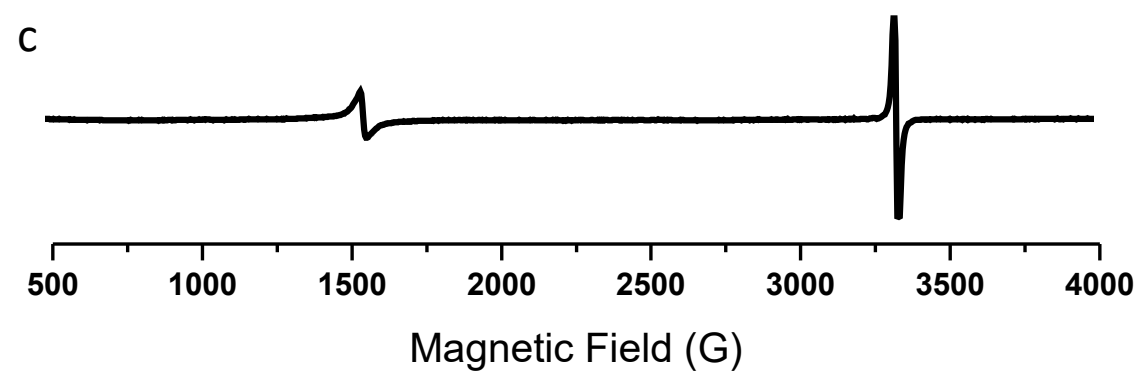

- Both simultaneous and sequential two-electron reduced species resulted in slow processes that ultimately led to the decomposition

Weeraratne, Baydoun and Verani et al., Dalton Trans., 2018, 47, 14351, Lanznaster and Verani et al, Inorg. Chem., $2006,45,955$. 


\section{Isothermal Compression and Film Characterization}
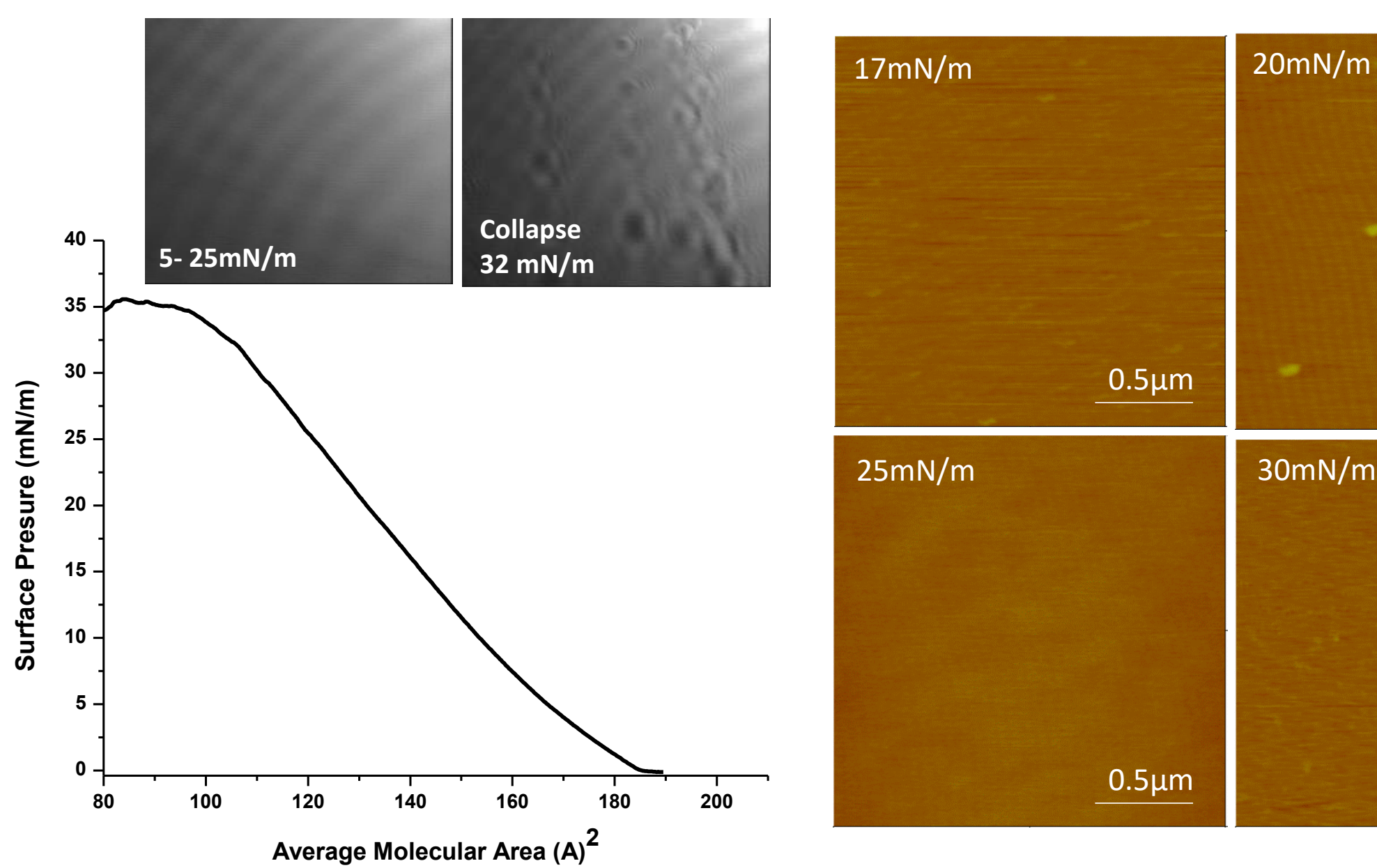

$0.5 \mu \mathrm{m}$

$30 \mathrm{mN} / \mathrm{m}$

$0.5 \mu \mathrm{m}$

- Area of interaction was $185 \AA^{2}$ per molecule and collapse pressure was at $32 \mathrm{mN} / \mathrm{m}$

- Surface characterization shows formation of a smooth film at $25 \mathrm{mN} / \mathrm{m}$ 


\section{LB film Characterization (IRRAS)}
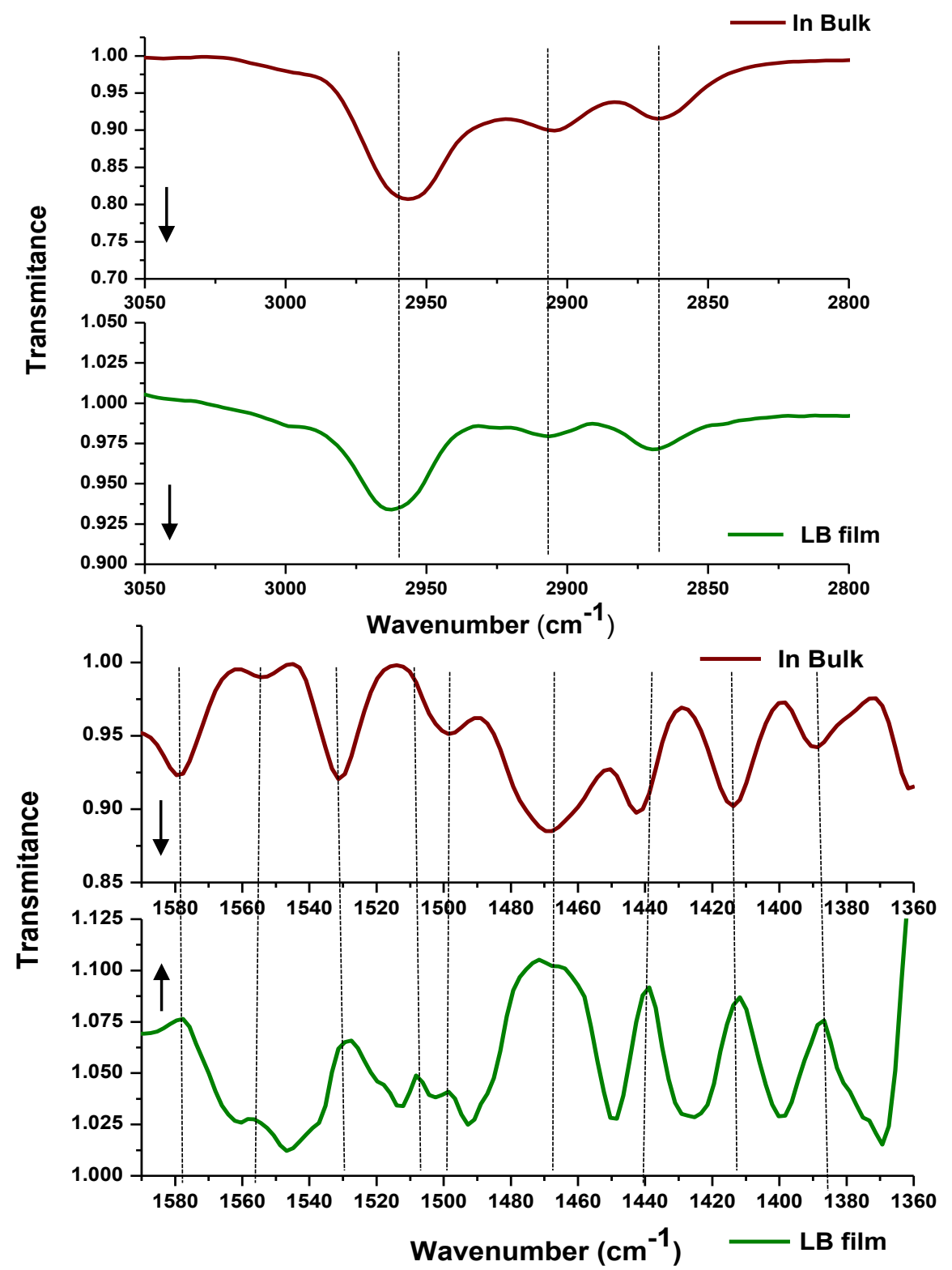

Weeraratne, Baydoun and Verani et al., Dalton Trans. 2018, 47, 14351 


\section{Current Rectification Ability}

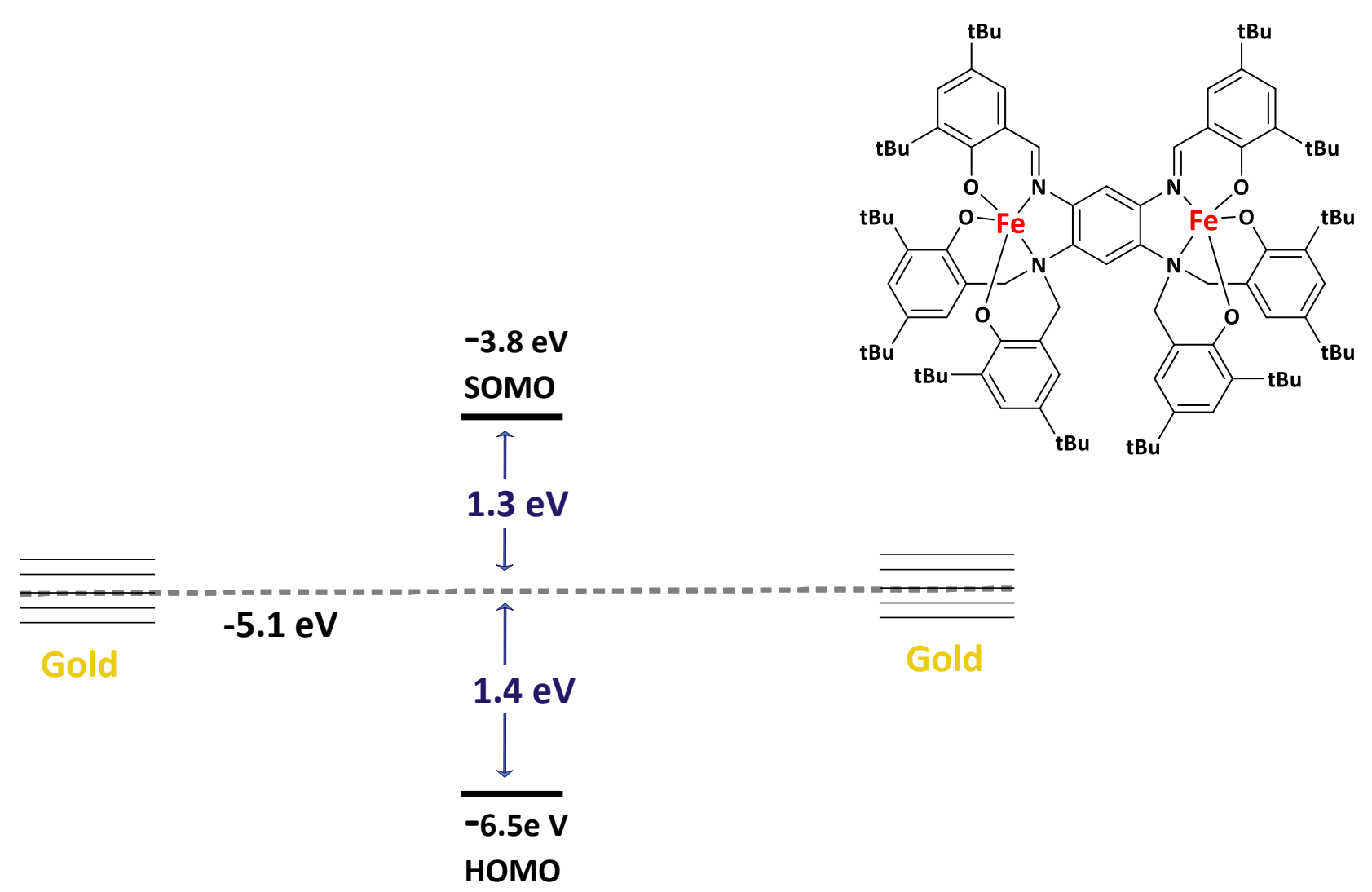

- Bimetallic iron(III) hydrophobe can be used as molecular rectifiers due to energetically compatible SOMO levels 


\section{$\underline{\text { Rectification Behavior }}$}
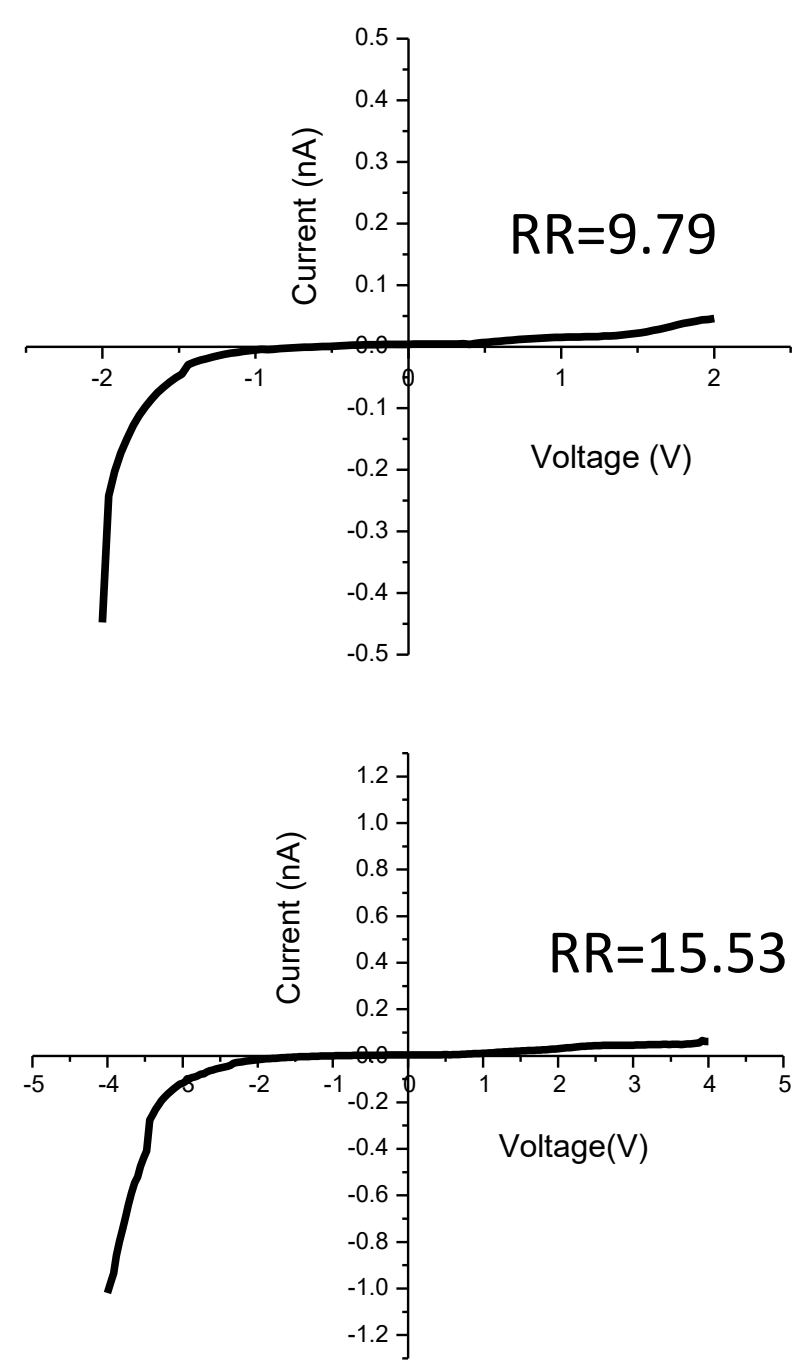

Optical Micrograph of the Assembly

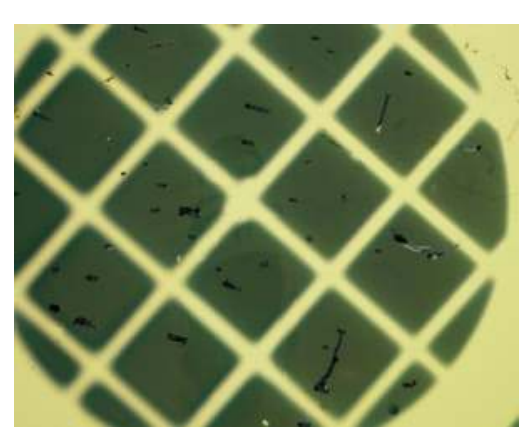

- I-V characteristics of the complex was measured using Au|LB-monolayer| Au device

- Rectification Ratio (RR) $=\frac{\left|\mathrm{I} a t-\mathrm{V}_{\mathrm{o}}\right|}{\left|\mathrm{I} a t+\mathrm{V}_{\mathrm{o}}\right|}$

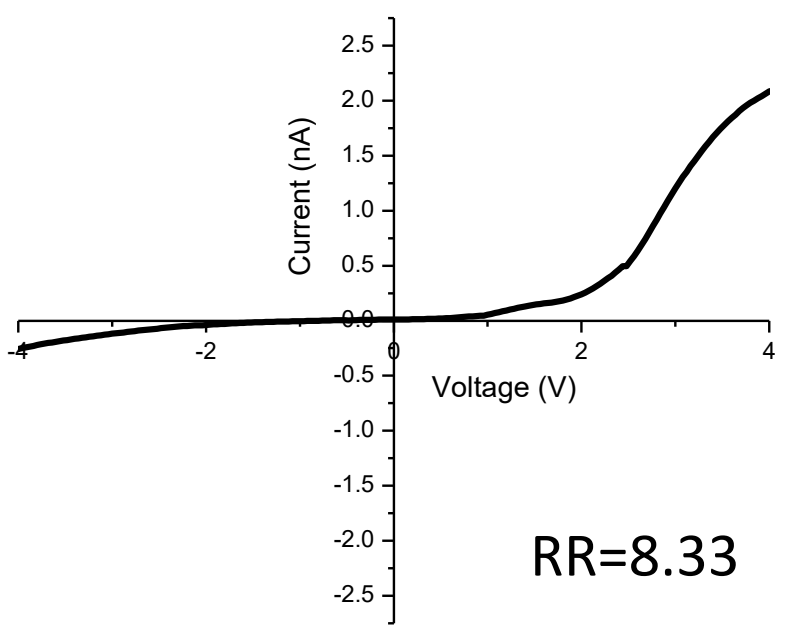




\section{Thickness of the LB films}

\section{Thickness Data}

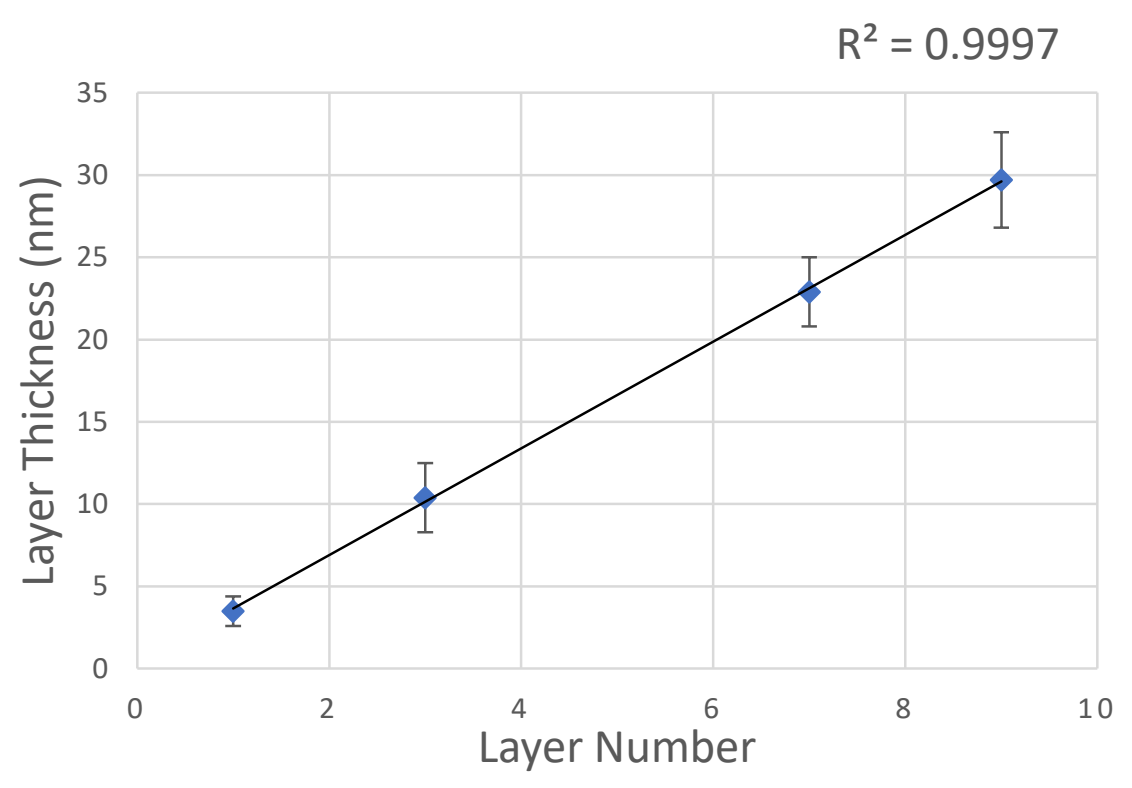

- The thickness of the monolayer is $34 \AA$

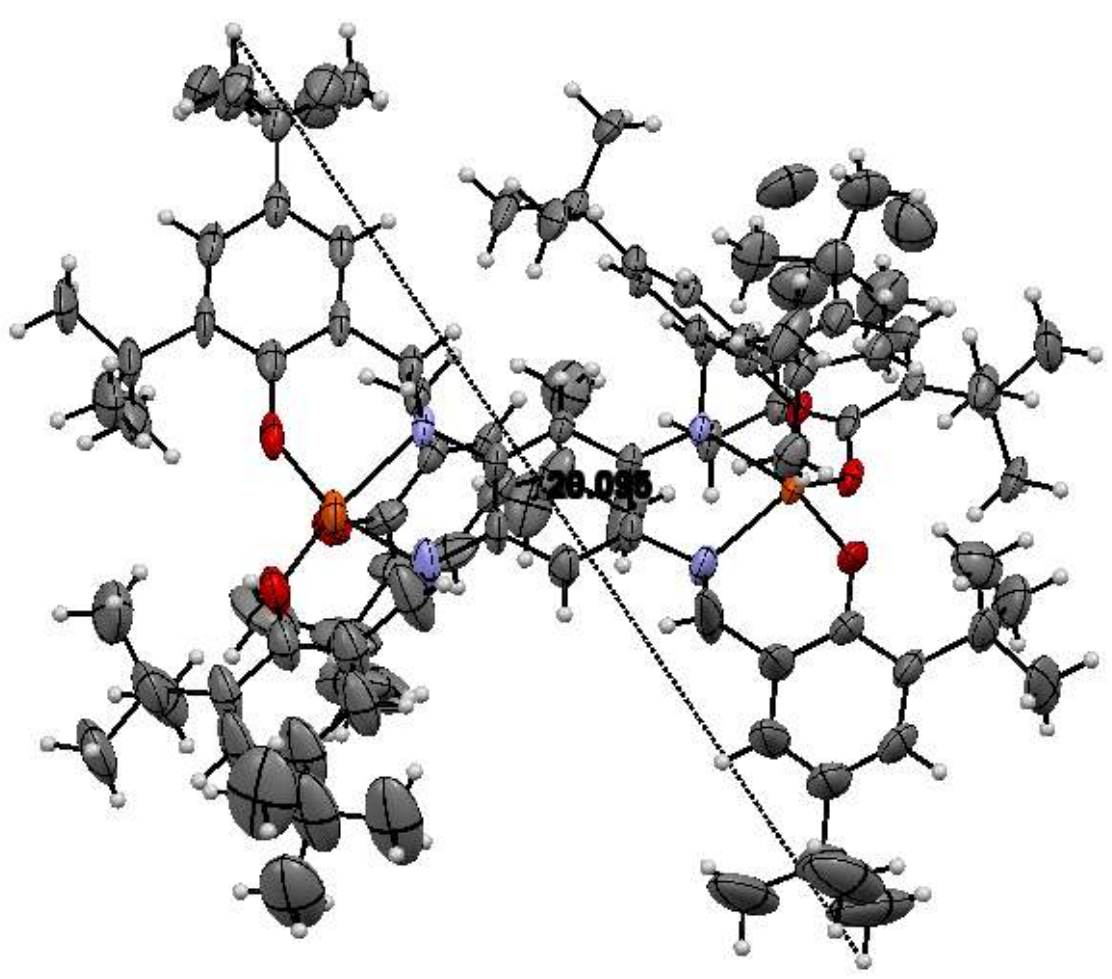

- The longest intramolecular distance obtained from the crystal structure reaches $20 \AA$ 


\section{Conclusions}

- We have successfully developed and studied redox, electronic and rectification properties of bimetallic iron(III) complex

- This complex forms homogeneous film at the air-water interface showing a moderate collapse pressure of $32 \mathrm{mN} \mathrm{m}^{-1}$

- CV suggest that two metal centers are moderately coupled and facilitate SOMObased electron transport, enabled current rectification

- Devices were fabricated using the iron(III) complex, current/voltage measurements were taken and the I-V responses indicate the rectification behavior

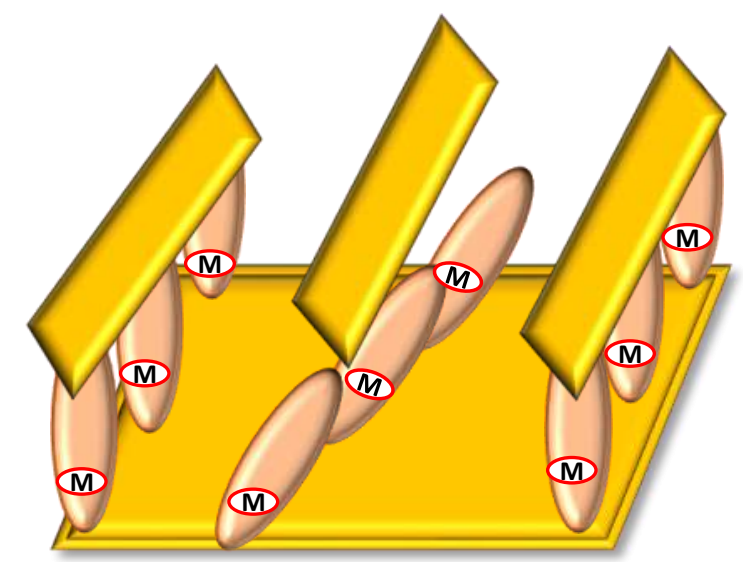




\section{Acknowledgements}

Advisor:

Prof. Cláudio Verani

\section{Present Group}

Members:

Samudra Amunugama

Fredricka Morgan

Abbie Cousino

Gibson Kirui

Eva Mwakazi

Past Group Members

Dr. Nour El Harakeh

Dr. L. Wickramasinghe

Dr. Sunalee Gonawala

Dr. Habib Baydoun

Dr. Kenneth Kpogo

Dr. Danushka Ekanayake

Dr. Pavithra Hettiarachchi

Renata Batista

Krista M. Kulesa

Jordyn Burdick

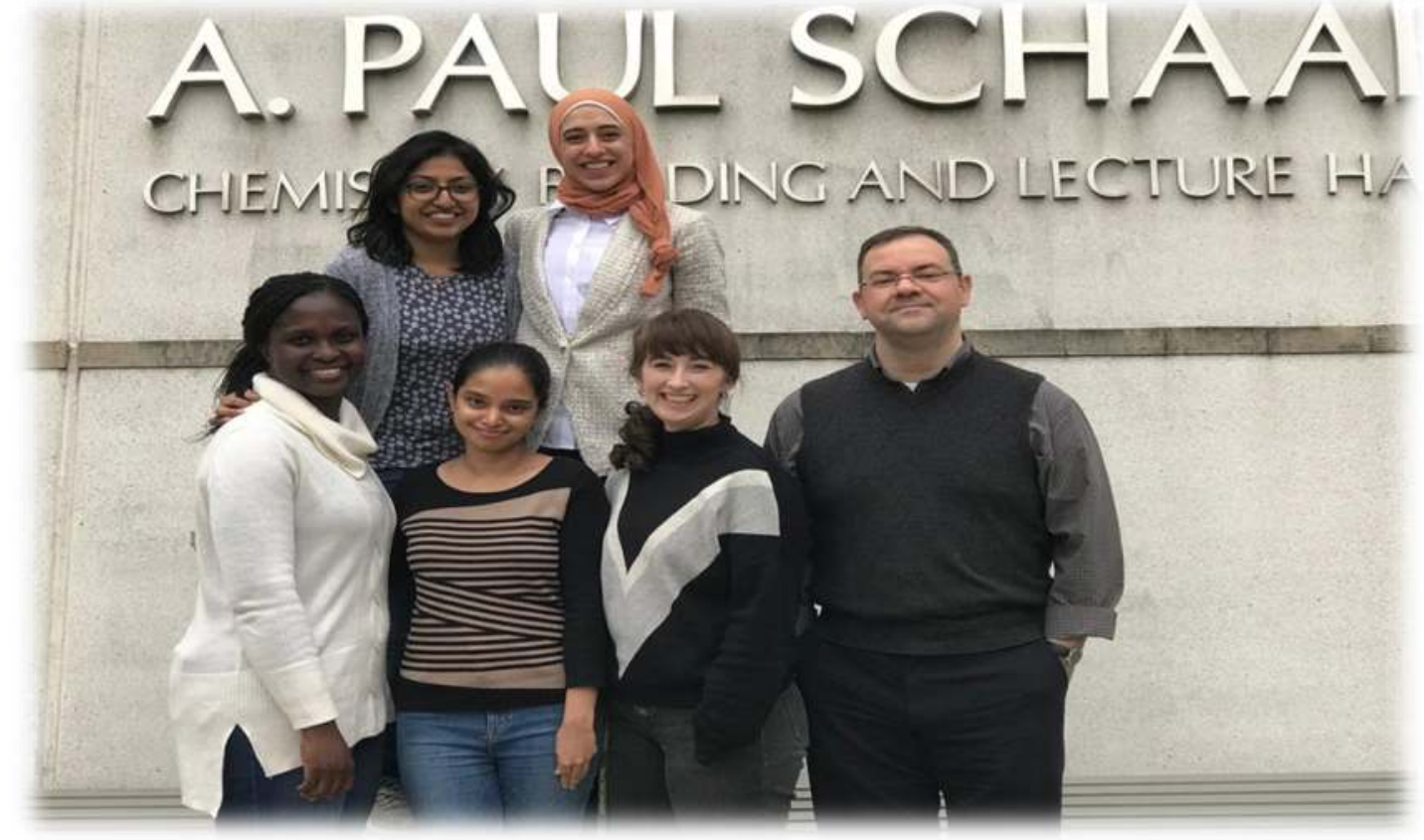

Collaborators

Prof. G. Mao; Dr. L. Xie (AFM)

Dr. O. Poluektov, Dr. J. Niklas (EPR)

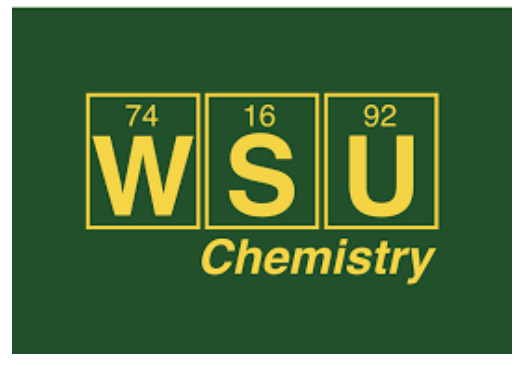

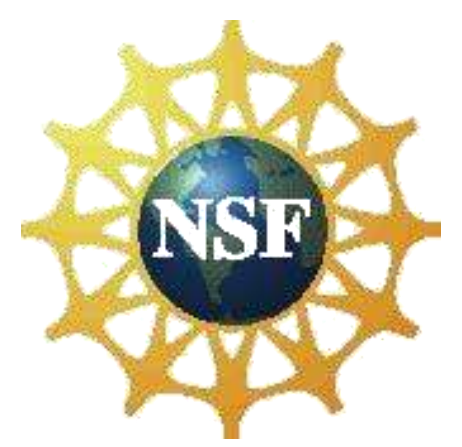

